\title{
ROBÓTICA, ECOLOGIA DOS SABERES E CTSA
}

Aline Lopes Rebouças Gomes ${ }^{1}$

Marcelo Paraíso Alves ${ }^{2}$

Resumo: Esta pesquisa objetivou investigar as ações de ensino vinculadas à perspectiva de CTSA realizadas pelos(as) estudantes do projeto de robótica denominado: Roboticando no Rubão. O escopo metodológico se aproximou dos estudos do cotidiano, mais especificamente via pesquisa com o cotidiano, pois estávamos mergulhados(as) nas práticas de aprendizagem e ensino junto com os(as) estudantes. A produção de dados se desenvolveu por intermédio de duas ações complementares: rodas de conversa com os(as) estudantes e caderno de campo. Os dados produzidos revelaram que as práticas desenvolvidas pelo projeto possuem potencial emancipatório, visto os sinais da produção coletiva a partir da participação e solidariedade.

Palavras-chave: Cotidiano; Educação Básica; Robótica; CTSA.

Abstract: This study aims to investigate the teaching actions linked to the CTSA perspective carried out by students in the robotics project called: Roboticando no Rubão. The methodological scope came close to everyday studies, more specifically via research with everyday life, as we were immersed in the learning and teaching practices together with the students. The production of data was developed through two complementary actions: conversation circles with students and field notebooks. The data produced revealed that the practices developed by the project have emancipatory potential, given the signs of collective production based on participation and solidarity.

Keywords: Daily life; Basic education; Robotics; CTSA.

${ }^{1}$ Centro Universitário de Volta Redonda. E-mail: alinelrgomes@gmail.com.

2 Centro Universitário de Volta Redonda. E-mail: marceloparaiso@outlook.com. 


\section{Introdução}

A presente pesquisa possui como centralidade as ações educativas desenvolvidas em uma escola pública da rede municipal de ensino de Volta Redonda, especificamente em uma comunidade marcada pela vulnerabilidade social (MARQUES; MATOS, 2016), visto que o referido espaço é caracterizado pela desigualdade e pelos diversos conflitos de ordem social.

Diante desse cenário excludente, e entendendo e concordando com Santos (1998; 2010; 2020), que considera o projeto de modernidade em crise sem ofertas de melhores expectativas para a sociedade atual, somado à educação moderna que apenas reproduz as características de exclusão da sociedade neoliberal, surgiu o interesse pela visibilização da experiência social curricular da Escola Municipal Rubens Machado (EMRM), onde os(as) estudantes e os(as) docentes dos anos finais do Ensino Fundamental foram concebidos como sujeitospraticantes ${ }^{3}$ que, mergulhados no cotidiano escolar, se constituíram como criadores da própria ação educativa, o que Oliveira (2012) denomina de "criação cotidiana de currículo".

Diante do exposto, é importante frisar que, historicamente, a escola supramencionada optou por desenvolver suas ações educativas centradas em projetos pedagógicos, contemplando os anseios, as necessidades e as demandas dos(as) estudantes que habitam o referido espaçotempo.

Nessa linha de pensamento, concebemos tais projetos como práticas emancipatórias e salientamos que são reconhecidos pela comunidade escolar com as seguintes denominações: Projeto Viderde Esporte, Dança, Teatro, Artesanato, Projeto Horta. Todavia, o presente estudo busca como centralidade das discussões o Projeto Roboticando no Rubão, que estabelece diálogos com a perspectiva de CTSA (Ciência, Tecnologia, Sociedade e Ambiente).

Diante do exposto, cabe refletir: Quais as contribuições do projeto de robótica para a iniciação científica na ótica de CTSA e em decorrência para a discussão em Educação Ambiental (EA)? No intuito de responder ao questionamento, a pesquisa objetivou investigar as ações de ensino vinculadas à perspectiva de CTSA realizadas pelos(as) estudantes do projeto de robótica denominado Roboticando no Rubão.

\section{CTSA: um possível olhar a partir da Ecologia dos Saberes}

Sabemos que os currículos de Física e Ciências devem dar ênfase ao desenvolvimento tecnológico e científico, incluindo conteúdos que

\footnotetext{
${ }^{3}$ A grafia a partir da junção de palavras segue a proposta teórico-metodológica da professora Nilda Alves (2003) que, no intuito de reinventar e recriar outras tantas palavras, busca em tal ação romper com a dicotomia implantada pela ciência clássica: teoria/prática, ensino/aprendizagem, natureza/cultura, dentre outras.
} 
proporcionem os(as) estudantes o entendimento sobre o funcionamento e a utilização dos dispositivos tecnológicos e os impactos que estes propiciam no desenvolvimento social e ambiental (VILCHES; GIL-PÉREZ; PRAIA, 2011).

De outro modo, Fourez (2003) menciona que o desenvolvimento de CTSA pode se desenvolver por dois caminhos: primeiro, o que concebe os conhecimentos científicos como avanços de uma sociedade que busca 0 progresso; segundo, o que concebe a construção científica e tecnológica viabilizada por determinantes históricos, culturais, sociais, políticos e econômicos. Para o autor, se, de um lado, o primeiro se constitui a partir de uma neutralidade política e ideológica escamoteando uma vulnerabilidade tecnocrática. por outro, a segunda vertente, apesar de reconhecer os avanços científicos e tecnológicos, não considera que estão ausentes de valores.

Apresentar as correntes supramencionadas não se deve por uma intenção de hierarquizá-las, muito menos no intuito de tentar capturar a complexidade que envolve o movimento educativo em torno do CTSA, mas na tentativa de contextualizar e trazer para o cenário de discussão e, em decorrência, para os(as) docentes que pretendem estabelecer um diálogo com tais conhecimentos, os saberes que permitam uma aproximação das características e ações no campo de CTSA.

Diante do exposto, salientamos que a presente pesquisa se utiliza dos pressupostos oriundos da noção de conhecimento prudente, conforme preconizado por Santos (2006). Para o autor, o conhecimento científico pautado no pensamento moderno entrou em crise e já não responde às demandas da sociedade contemporânea, visto que são vários os sinais que revelam o seu esgotamento e a sua irreversibilidade.

Tendo como pressuposto que o pensamento moderno, no decorrer dos últimos séculos (SANTOS, 2002), privilegiou no pilar da regulação o princípio do mercado, bem como centrou suas ações no conhecimento científico e, em decorrência, na emancipação esgotou-se na própria regulação, pois o conhecimento científico, ao tornar-se a única forma de racionalidade, acarretou a hipercientificização da emancipação e a hipermercadorização da regulação, não é por acaso que as intervenções científicas e tecnológicas centralizam suas ações no capital em detrimento da sociedade e da humanidade.

Atualmente, Santos (2020) nos chama a atenção ao nos mostrar como o capital se apresenta em meio à Pandemia da SARS-CoV-2, pois a corrida laboratorial para a produção da vacina ao combate do vírus deveria ter como preocupação o bem comum e não o lucro com sua venda.

Nesta linha de pensamento, ao refletir sobre a crise explicitada, nos exige reconhecer que, de alguma maneira, enfrentamos um conflito entre os pilares da regulação e da emancipação (SANTOS, 2001). Tal conflito nos move a uma discrepância entre experiências e expectativas: as políticas de austeridade implantadas no Brasil, a partir de 2015, são exemplos do que estamos a ressaltar (SANTOS, 2015). 
Ao considerar o exposto, entendemos que a modernidade, ao se assentar em dois pilares (regulação e emancipação), se configura por meio de três princípios complexos: Regulação - princípio do estado, mercado e comunidade; e a Emancipação via racionalidade estético-expressiva da arte e da literatura, racionalidade moral-prática da ética e do direito e a racionalidade cognitivo instrumental da ciência e da técnica (SANTOS, 2001).

Diante desse cenário, do inconformismo perante as consequências apresentadas, bem como à crítica ao colonialismo, ao patriarcado, ao capitalismo e à epistemologia moderna, Santos $(2002 ; 2010)$ nos propõe outro paradigma centrado na noção de conhecimento prudente. Tal noção toma como base a racionalidade estético-expressiva, por ser a dimensão capaz de resguardar e condensar "melhor as antinomias da situação presente e, portanto, aquela em que são mais fortes os sinais do futuro" (SANTOS, 2002, p. 92). Do mesmo modo, Santos (2002, p. 75) trabalha com a ideia de que no pilar da regulação, a comunidade foi o princípio menos obstruído, portanto, "o mais bem colocado para instaurar uma dialética positiva com o pilar da emancipação".

Assim, ao partir da lógica estabelecida pelo pensamento prudente, (SANTOS, 2002), devemos considerar que no princípio da comunidade é necessário o desenvolvimento de duas dimensões: a participação e a solidariedade, visto que, durante o processo de constituição da modernidade e da instauração do capitalismo, a comunidade foi reduzida a sua ação política: democracia representativa.

No que pese a Racionalidade Estético-Expressiva da Arte e da Literatura, as dimensões de autoria, prazerosidade e artefactualidade discursiva, não permitiram o seu enclausuramento, pois a arte e o prazer não são passíveis de aprisionamento.

Partindo da lógica estabelecida, a comunidade e o conhecimento prudente são pensados na articulação entre a comunidade e a racionalidade estético-expressiva, pois entendemos que os fundamentos de uma Educação Ambiental (EA) emancipatória deveria também privilegiar a aproximação à noção de comunidade interpretativa, visto que esse espaço se configura como um local que defende a superação da perspectiva monocultural, visto que a referida comunidade privilegia outros repertórios para a compreensão dos múltiplos contextos (SANTOS, 2002).

Para Jacobi, Tristão e Franco (2009, p. 71), tais comunidades "ocorrem quando há uma ampliação do discurso argumentativo nos auditórios relevantes da retórica, isto é, abrem-se possibilidades de superação do monopólio interpretativo e do conhecimento de uma só via".

Nesse sentido, a solidariedade e a participação seriam características fundamentais nessa comunidade, porque são "traduzida[s] por um conjunto de princípios ou por fonte de critérios percebidos como um saber decisivo para 
garantir o futuro da humanidade" (TRISTÃO, 2005, p. 255) e, respectivamente, como um modo de cuidar do planeta.

Já a participação, no interior da comunidade interpretativa, intenciona a intervenção a partir da Educação Ambiental, podendo ser concebida como um espaço político, conforme ressalta Tristão (2005, p. 258): "[...] quanto mais amplo for o domínio da política, maior será a liberdade e, consequentemente, a participação".

Sendo a perspectiva de CTSA potencialmente aglutinadora dos conhecimentos que estão na base do modo como estabelecemos nossas intervenções no planeta, convém refletir acerca da relação que Santos (2010) convida a trilhar como percurso que privilegia o pragmatismo epistemológico, que possibilita ou impede certas intervenções no mundo: epistemologia das consequências. Tal perspectiva deve reavaliar as intervenções e as relações "reais" na sociedade e no meio ambiente, de modo a prevenir os impactos que possam promover, de acordo com o princípio da precaução: "Deve dar-se preferência às formas de conhecimento que garantam a maior participação dos grupos sociais envolvidos na concepção, na execução, no controle e na fruição da intervenção" (SANTOS, 2010, p. 60).

\section{Projeto Roboticando no Rubão, CTSA e Educação Ambiental}

Partindo dos pressupostos estabelecidos por Santos (2002; 2010; 2011 ; 2020), passaremos a delinear os saberes que podem ser concebidos como caminhos de proposição teórico-metodológica para o fortalecimento das práticas emancipatórias que, em forma de ações pedagógicas, se aproximam de uma possível Educação Ambiental.

Para que a Educação Ambiental experienciada em comunidades interpretativas possa construir um conhecimento-emancipação, capaz de criar um novo senso comum ético e estético, torna-se necessário superar a capacidade de conceber o "outro" como objeto, típico do colonialismo tão hegemonicamente imposto durante a modernidade.

A expressão "comunidades interpretativas" já foi aproximada ao campo da Educação Ambiental pelos autores Avanzi e Malagodi (2005) e Avanzi (2005), e apresentada como o encontro entre diferentes interpretações da realidade, o que permite que seja construída uma compreensão mais ampla do que seria alcançado individualmente por um único intérprete. Centralmente, traz a noção da importância do outro em nosso movimento de produzir significados e sentidos, na reciprocidade entre indivíduos que partilham territórios físicos e simbólicos.

Assim, ao partir do pilar da emancipação, especificamente atravessada pela racionalidade estético-expressiva e as noções de prazer, autoria, artefactualidade discursiva, articulada ao pilar da regulação pelo princípio da comunidade viabilizada pela solidariedade e participação, Tristão (2005, p. 
257), ao discutir a Educação Ambiental, nos chama a atenção para a potência da formulação supramencionada no intuito de garantir que a solidariedade estabeleça uma dimensão ética ao conhecimento-emancipação. E, por sua vez, a participação, pelo caráter qualitativo e o seu envolvimento efetivo e responsável com a dimensão política. A autora assegura que, "como seres humanos, dependemos da solidariedade que, por sua vez, pressupõe a participação" (Figura 1).

Diante do exposto, gostaríamos de trazer para o debate algumas práticas ${ }^{4}$ educativas desenvolvidas no cotidiano do projeto de robótica.

A primeira prática educacional emerge da fabricação da lixeira desenvolvida com material reciclado - garrafas de cinco litros de açaí - com sensores e atuadores conectados à placa de programação com o uso do Arduíno ${ }^{5}$ acoplado a um Shield de $\mathrm{MP}^{6}$ para reprodução do áudio que identifica o tipo de material a ser coletado (Figura 1).

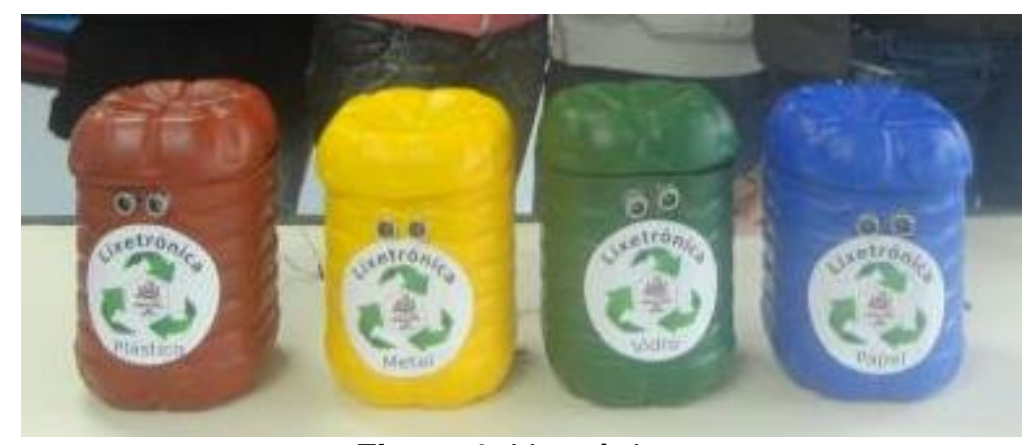

Figura 1: Lixetrônica.

Fonte: Arquivo iconográfico da Escola Municipal Rubens Machado.

Cabe frisar que a produção supramencionada é entendida como uma fabricação (CERTEAU, 1994) que emerge na tessitura da perspectiva socioambiental emancipatória defendida no trabalho junto com os conhecimentos oriundos de CTSA, pois emerge de uma coletividade que atua de modo colaborativo e solidário na solução de problemas que afetam 0 cotidiano escolar.

\footnotetext{
${ }^{4}$ A prática no presente estudo é entendida como uma "combinação mais ou menos coerente, mais ou menos fluida, de elementos cotidianos concretos ou ideológicos, ao mesmo tempo passados por uma tradição e realizados dia a dia através dos comportamentos que traduzem uma visibilidade social [...]". Assim, ao considerarmos que "prático vem ser aquilo que é decisivo para a identidade de um usuário ou de um grupo", estamos concebendo-a como uma ação particular, singular do coletivo que participa do projeto de robótica investigado (CERTEAU, 1996, p. 39-40).

${ }^{5}$ É um dispositivo menos custoso, funcional e fácil para ser utilizado em programação, portanto, tornando-se acessível à área da educação e/ou projetistas amadores. Todavia, também é reconhecido como um hardware livre, democratizando sua montagem e modificação.

6 Placa que pode ser utilizada tanto para reproduzir quanto para gravar sons.
} 
Assim, no ano de 2013, a docente responsável e a equipe idealizadora da Lixetrônica, escreveram um trabalho e o submeteram à Mostra Nacional de Robótica (MNR). A Mostra Nacional de Robótica (MNR) é uma mostra científica de âmbito nacional cujo objetivo é expor e divulgar trabalhos na área de Robótica, estimulando e divulgando a produção de trabalhos científicos e inovações tecnológicas e metodológicas que podem contribuir significativamente para o desenvolvimento de uma área do conhecimento.

A mostra é realizada articulada a eventos ou Feiras de Ciências ou Mostras Científicas que reúnem participantes que exibem e/ou demonstram seus trabalhos pessoalmente, utilizando recursos diversos (imagens, vídeos, sons, desenhos, textos) para ilustrar a apresentação. Tais eventos também se destinam a estudantes matriculados(as) no ensino fundamental, médio, técnico e pré-vestibular em instituição oficial de ensino pública ou privada, bem como de cursos superiores, pós-graduação e/ou pesquisadores da área.

A aprovação do trabalho submetido à MNR, além de conceder a possibilidade de a escola representar o município de Volta Redonda em Fortaleza, também recebeu a concessão de uma bolsa de estudos da Comissão Nacional de Desenvolvimento Científico e Tecnológico (CNPq) a uma estudante da escola. A escola, que até então era invisível para a Secretaria Municipal de Educação, não apenas por ter sua localização periférica, mas também pelos problemas cotidianos de vulnerabilidade social que a impacta, passava a ocupar lugar de destaque em decorrência das maneiras de usarfazer (CERTEAU,1994) saberes científicos.

Com a participação da equipe na MNR, no período de 6 a 20 de outubro de 2013, em Fortaleza/CE, a mesma observou a necessidade de aperfeiçoar a Lixetrônica, criando uma logomarca para o projeto Roboticando no Rubão e para a Lixetrônica (Figura 2).

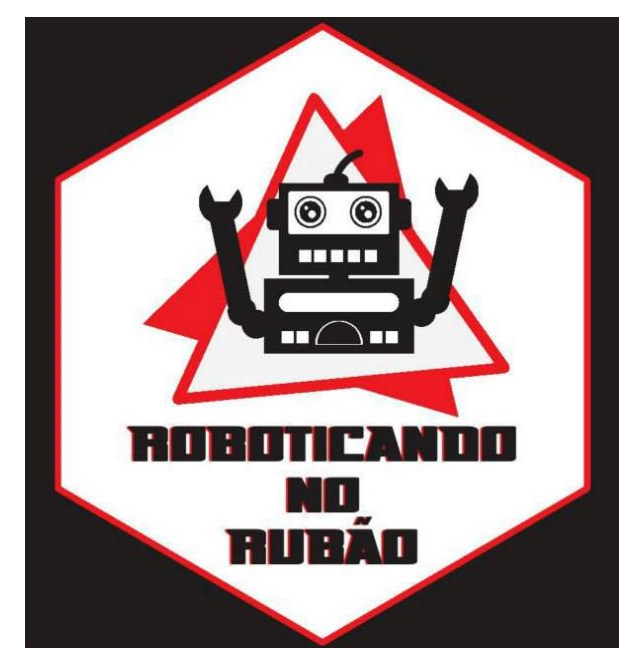

Figura 2: Logomarca do projeto Roboticando no Rubão Fonte: Arquivo iconográfico da E.M. Rubens Machado. 
Outro indício (GINZBURG, 1989) que nos revela as estratégias utilizadas para a otimização de materiais no desenvolvimento do projeto emerge na narrativa do estudante B:

Estudante B: Reutilizamos alguns motores dos nossos recursos sustentáveis, para a automação dos protótipos são utilizados componentes eletrônicos, não recicláveis, para adquiri-los promovemos rifas e organizamos eventos na escola, com o objetivo de arrecadar recursos. (Grifos $\operatorname{dos}($ as) autores(as)).

A narrativa acima nos permite perceber o diálogo com o princípio da precaução, pois os(as) estudantes se preocupam com a reutilização de materiais intencionando uma robótica sustentável. Desse modo, existe uma preocupação na apreensão de materiais de celulares, computadores, impressoras, dentre outros equipamentos descartados que permitem 0 desenvolvimento de protótipos com o intuito de mediar a construção de conhecimentos dos estudantes: educação socioambiental.

Sabedores de que a Educação Ambiental, que se preocupa apenas com o descarte de resíduos sólidos, se aproxima de uma perspectiva conservadora, no cotidiano do projeto havia a preocupação de se problematizar os modos de produção característicos de uma sociedade capitalista (GUIMARÃES, 2004).

Assim, ao proporcionar uma robótica que contribua com a diminuição do consumo e do lixo a partir do reuso das peças, o projeto compreende a importância desse tipo de atividade para o aspecto socioambiental, centrando suas ações para o Desenvolvimento de Alfabetização Científica que prevê o entendimento das relações de CTSA.

De acordo com Sasseron e Carvalho (2008), a alfabetização cientifica é estruturada em três eixos: a) compreensão básica de termos, conhecimentos e conceitos científicos fundamentais; b) compreensão da natureza da ciência e dos fatores éticos e políticos que circundam sua prática; c) entendimento das relações existentes entre Ciência, Tecnologia, Sociedade e Meio Ambiente.

Os eixos acima estão relacionados ao desenvolvimento da linguagem científica, com enfoque em CTSA. As atividades desenvolvidas para as aulas de ciências, com o objetivo de contribuir para a alfabetização científica, devem seguir estes eixos, encorajando o senso crítico, a fim de identificar as relações com tal enfoque (CTSA).

Ainda com relação à Lixetrônica, gostaríamos de pensá-la a partir da noção de autoria, visto que, para Santos (2002), significa pensá-la articulada a outros conceitos que lhe são adjacentes: "[...] iniciativa, autonomia, criatividade, autoridade, autenticidade e originalidade" (SANTOS, 2002, p. 76). Para o autor, pensar a autoria requer considerar que a produção artística ou 
literária é "[...] irrepetível e inacabada" (SANTOS, 2002, p. 76), o que the confere um caráter singular e com aberturas e que a mantém resistente à colonização.

Nessa linha de pensamento, Gonçalves (2016), ao discutir a independência timorense em 2002, explicita que as artes de rua foram utilizadas como potencial emancipatório como resistência, visto que é possível produzi-las em "[...] qualquer parede ou rua do mundo, e com pouco acesso a recursos, chamar a atenção para uma causa ou tentar influenciar as ideias e perspectivas do outro" (GONÇALVES, 2016, p. 484).

A narrativa da estudante $\mathrm{J}$, participante do projeto durante três anos, revela evidências significativas sobre a autonomia dos estudantes na resolução de problemas da equipe:

Estudante J: Durante o projeto eu conseguia ver minhas ideias na prática, entende? Tipo, escolher cores e discutir o que o robô vai fazer... A professora aceitava nossas ideias e eu me sentia importante com isso. A equipe tinha que chegar a um acordo para definir o que seria feito, dessa maneira aprendemos a trabalhar em grupo. (Grifos dos(as) autores(as)).

No que pese a noção de autoria, fica evidenciada a participação dos(as) estudantes nos processos decisórios: cores, movimentos dos robôs, dentre outras ações. Tal participação possibilita uma produção singular, pois se considerarmos que as construções dos robôs emergem do coletivo de sujeitos envolvidos, em cada competição, a equipe se modifica, a temática se altera, e, portanto, a autoria das fabricações também, exigindo novas discussões, decisões e, ainda, outra produção possível para o coletivo que está envolvido no processo educativo.

Nessa ótica, o projeto Roboticando no Rubão se aproxima das discussões propostas solidariedade e participação e, em decorrência, às discussões propostas por Santos e Auler (2019). Para os autores (SANTOS; AULER, 2019), não há neutralidade científica, e, por isso, devemos necessariamente considerar a efetiva participação dos sujeitos nos processos decisórios da sociedade como um direito a ser conquistado, pois a suposta neutralidade da ciência e da tecnologia "[...] sustenta e legitima modelos decisórios tecnocráticos, podendo fragilizar a constituição de uma efetiva cultura de participação" (SANTOS; AULER, 2019, p. 486).

Outro aspecto que revela o envolvimento dos(as) estudantes com o protótipo pode ser percebido na narrativa a seguir: uma pessoa e outro componente da equipe deu a ideia 
para de transformá-la em uma LIXETRÔNICA, adaptada para pessoas com deficiência visual. Logo após, as garrafas foram encapadas e pintadas de acordo com as cores relacionadas a coleta seletiva. A voz reproduzida pelo sensor da lixeira era de um membro da equipe: Nesta lixeira descarte plástico. (Grifos dos(as) autores(as)).

Ao mergulharmos no cotidiano, percebemos o disposto por Certeau (1994, p. 94): "[...] subvertiam-nas a partir de dentro - não rejeitando-as ou transformando-as, mas por cem maneiras de empregá-las [...]". Certeau (1994) nos chama a atenção para o fato de não sermos consumidores passivos, pois, sempre que necessário, transformamos os produtos que nos chegam, de modo a reinventá-los.

Assim, foi possível perceber que as práticas do projeto Roboticando no Rubão são enredadas pelo diálogo entre os conhecimentos oficiais e outros tantos que circulam na sociedade. As aulas são sustentadas por atividades criativas e dinâmicas, nas quais os(as) estudantes participam efetivamente, demonstrando prazer e comprometimento com o projeto.

A autonomia do educando em uma sociedade que se pretenda democrática é, sobretudo, a possibilidade de ter uma compreensão própria das metas da tarefa educativa. Sem essa possibilidade, não há como falar em ética do professor e em ética da escola, e sem isso, a autonomia deixa de ser uma condição de liberdade e pode até ser facilitadora da opressão.

Outro indício (GINZBURG, 1989) que nos permitiu perceber o movimento do Projeto de Robótica aproximando-se do caráter ético-político participação e solidariedade - emerge da reutilização materiais descartados na produção do robô que permitiu a participação dos(as) estudantes na Mostra Nacional de Robótica, em João Pessoa, no ano de 2018 (Figuras 3 e 4).

Porém, gostaríamos agora de privilegiar outro elemento que compõe a comunidade interpretativa aqui estudada (Projeto de Robótica): a racionalidade estético-expressiva da arte e da literatura.

Parece-nos que a construção do robô para a VIII Mostra Nacional de Robótica, em João Pessoa no ano de 2018, também se aproximou da racionalidade estético-expressiva da arte e da literatura (SANTOS, 2002), pois percebemos, nas Figuras 3 e 4, o enredamento entre a noção de autoria e artefactualidade discursiva.

Dessa forma, salientamos que a autoria aqui concebida estabelece uma interlocução com a produção artística ou literária, uma vez que é "irrepetível e inacabada" (SANTOS, 2002, p. 76), o que confere a ela um caráter particular e com aberturas, mantendo-se resistente ao processo capitalista e colonizador. A Figura 3 revela pistas da artesania da comunidade interpretativa, fragmentos que indiciam os modos de pensarfazer que se aproximam da bricolagem certeuniana, e, simultaneamente, da preocupação 
com o reaproveitamento de material descartável, uma possível Educação Ambiental, que, neste estudo, denominamos de EA com potenciais emancipatórios.

Nesse sentido, gostaríamos de nos aproximar do estudo de Gonçalves (2016) que, ao discutir o modo de produção artesanal, considerou que as artes de rua foram utilizadas como potencial emancipatório, como resistência, visto que é possível produzi-las em "[...] qualquer parede ou rua do mundo, e com pouco acesso a recursos, chamar a atenção para uma causa ou tentar influenciar as ideias e perspectivas do outro" (GONÇALVES, 2016, p. 484).

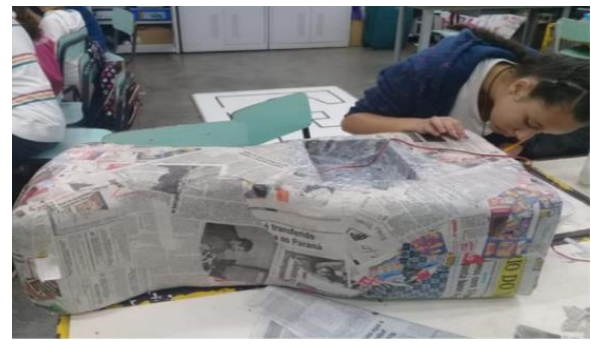

Figura 3: Produção do Robô material reciclável

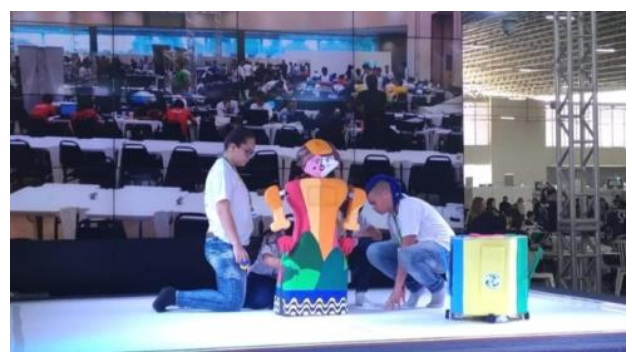

Figura 4: Robô na competição

Fonte: Arquivo iconográfico da E.M. Rubens Machado.

A narrativa da estudante $\mathrm{J}$, participante do projeto durante três anos, revela evidências significativas sobre a autonomia dos estudantes na resolução de problemas da equipe:

Estudante J: Durante o projeto eu conseguia ver minhas ideias na prática, entende? Tipo, escolher cores e discutir o que o robô vai fazer... A professora aceitava nossas ideias e eu me sentia importante com isso. A equipe tinha que chegar a um acordo para definir o que seria feito, dessa maneira aprendemos a trabalhar em grupo. (Grifos dos(as) autores(as)).

A narrativa reproduzida acima revela evidências (GINZBURG, 1989) que nos permitiram perceber fragmentos da participação e a autonomia dos(as) estudantes nos processos decisórios: [...] A professora aceitava nossas ideias [...]". Seguindo essa linha de pensamento, Oliveira (2013b, p. 9), considera que a autoria "assegura a dimensão ativa do sujeito na produção de conhecimentos e práticas sociais. $O$ autor é originador, é sujeito, sem que, para isso, tenha que definir seus temas e obras como objetos controláveis e manipuláveis [...]".

Assim, ao recuperar a noção de autoria e a respectiva autonomia/intencionalidade em sua produção, percebemos a presença da artefactualidade discursiva no modo como o robô foi pensadofabricado, com vistas à emancipação social, considerando a participação destes em um evento de iniciação científica em âmbito nacional. A esse respeito, Santos (2002, p. 77) considera que a artefactualidade discursiva se constitui como outro 
"conceito organizador do domínio artístico e literário", visto que "[...] as obras de arte têm de ser criadas ou construídas. São o produto de uma intenção específica e de um ato construtivo específico".

Em outro momento, Santos (2018, p. 103) nos remete a pensar na relevância da artefactualidade para os processos emancipatórios, ao afirmar que na construção de "um mundo novo, inventar novas formas de sociabilidade, atravessar terras-de-ninguém entre limites variáveis - tais são as experiências de artefactualidade mais fortes que podemos imaginar".

\section{Considerações}

Sabendo que o estudo objetivou investigar as ações de ensino vinculadas à perspectiva de CTSA realizadas pelos(as) estudantes do projeto de robótica de uma escola pública de Volta Redonda-RJ, consideramos que: a) a produção dos(as) estudantes (fabricação dos robôs) demonstram evidências emancipatórias, visto que apresentam características discursivas que não se reduzem aos pressupostos rigorosos da ciência moderna; b) as produções apresentadas no estudo (logomarca, lixetrônica, robôs) enredam-se ao domínio organizador da racionalidade artística e literária e à perspectiva solidária e cooperativa, que são dimensões fundantes na $E A ; b)$ as narrativas e as práticas nos deram evidências de que o projeto permitiu a constituição de uma comunidade que atua na escola de modo a produzir um conhecimento que emerge do diálogo entre os(as) estudantes e a professora. Tal indício emerge na narrativa discente ao trazer a possibilidade da participação do grupo nos processos decisórios.

Para finalizar, gostaríamos de reafirmar o potencial emancipatório apresentado pelo Projeto Roboticando no Rubão, pois, considerando o modo como os(as) estudantes participam das práticas socioculturais aqui apresentadas, e tantas outras que permaneceram "excluídas" deste artigo, diante dos limites textuais, fica evidenciado o modo peculiar da luta que os(as) praticantes que habitam o referido espaçotempo do projeto pensamfazem de modo astuto, inventivo e criativo; luta pela justiça cognitiva, pois sabemos que sem ela não nos é possível lutar por justiça social (SANTOS, 2007).

\section{Referências}

AVANZI, M.R.; MALAGODI, M.A.S. Comunidades Interpretativas. In: FERRARO JÚNIOR, L.A. (org.). Encontros e Caminhos: formação de educadores ambientais e coletivos educadores. Brasília: MMA, 2005. p. 93-102.

CARVALHO, J.M. O cotidiano escolar como comunidade de afetos. Petrópolis, RJ: DP et Alii; Brasília/DF; CNPq, 2009.

CERTEAU, M. A invenção do cotidiano: artes de fazer. Petrópolis: Vozes, 1994. 
FOUREZ, G. Crise no Ensino de Ciências? Investigações em Ensino de Ciências, Porto Alegre. Instituto de Física da UFRGS, v. 8, n. 2, ago. 2003.

GINZBURG, C. Mitos, emblemas e sinais: morfologia e história. 2. ed. São Paulo: Companhia das Letras, 1989.

MIGNOLO, W.D. Histórias locais/Projetos globais: colonialidade, saberes subalternos e pensamento liminar. Belo Horizonte: Editora UFMG, 2003. p. 505.

OLIVEIRA, I. B. Currículo como criação cotidiana. Petrópolis-RJ: DP et Alii, 2012.

RICARDO, E. C. Debate educação CTSA: obstáculos e possibilidades para sua implementação no contexto escolar. Ciência e Ensino, [s.I.], v. 1, p. 1-12, 2007.

ALVES, R. Rimas das ruas. Revista Z, Rio de Janeiro [on-line], n. 2, 2014. Disponível em: http://revistazcultural.pacc.ufrj.br/rimas-das-ruas/. Acesso em: 21 jul. 2016.

SANTOS, B.S. A gramática do tempo: para uma nova cultura política. São Paulo: Cortez, 2006.

SANTOS, B.S. A crítica da razão indolente: contra o desperdício da experiência. São Paulo: Cortez, 2000.

SANTOS, B.S. (org.). Conhecimento Prudente para uma vida Decente. São Paulo: Cortez, 2004.

SANTOS, B.S. O fim do Império Cognitivo. São Paulo: Cortez, 2018.

SANTOS, B.S. Para além do pensamento abissal: das linhas globais a uma ecologia de saberes. In: SANTOS, B. S.; MENESES, M. P. Epistemologias do Sul. São Paulo: Cortez, 2010.

SANTOS, B.S. A crítica da razão indolente: contra o desperdício da experiência. São Paulo: Cortez, 2002.

SANTOS, W.L.P.; MORTIMER, E.F. Uma análise de pressupostos teóricos da abordagem CTS (Ciência, Tecnologia, Sociedade) no contexto da educação brasileira. Ensaio Pesquisa em Educação em Ciências, Belo Horizonte, v. 2, n. 2, p. 110-132, 2000.

SANTOS, R. E. (org.). Questões urbanas e racismo. Petrópolis, RJ: DP et Alii; Brasília: ABPN, 2012.

TRISTÃO, M. A Educação Ambiental na formação de professores: redes de saberes. São Paulo: Annablume, 2004. 236 p.

VILCHES, A.; GIL-PÉREZ, D.; PRAIA, J. De CTS a CTSA: educación por um futuro sostenible. In: SANTOS, W. L. P.; AULER, D. (org.). CTS e Educação Científica: desafios, tendências e resultados de pesquisa. Brasília, DF: Editora Universidade de Brasília, 2011. p. 185-209. 